\title{
THE EXISTENCE OF COMMUNITY SPACES OUTSIDE THE FLAT BLOCK AFFECTED BY ACTIVITIES OF LOW- INCOME RESIDENTS
}

\author{
Ratna Darmiwati * \\ *) Darma Cendika Catholic University
}

\begin{abstract}
Culture as a system includes ideas, concepts, rules, and meanings. It underlies the expression of human life and a system of common sense as a result of the social process. It emphasizes an abstract thing rather than concrete ones. Behavior as cultural expressions deals with the relationship between one another. The resident's social activities cannot be implemented as desired which causes them to find new places that can meet the user's behavior and culture. If the behavior and community space used are appropriate, they will continue to develop their lives in the same place. Furthermore, they can attract people from other blocks to join.

The process of utilizing existing facilities and treating nature according to the social system of low-income users need environmental adaptation. This study explores the existence of community spaces outside the building in a flat environment related to the behavior and culture of residents as users. This assessment is based on community togetherness in community spaces, either planned or unplanned.

The research method used is Descriptive-Qualitative-Exploratory, with interviews of selected respondents. The number and the origin of residents who gathered in the community with various activities are the indications of the suitability of the community space. Low-income residents generally meet somewhere with a variety of diverse needs. The existence of planned community space is used maximally. This space is used by many people for various needs. For low-income residents, this place can meet their interests simultaneously. It means that the place will be used based on the functions, the fragmentation of togetherness, focused activities, consistency, the user's character, affordability, and environment order.
\end{abstract}

Keywords: Planned community space, unplanned community space, flat environment, low-income flat 


\section{INTRODUCTION}

Surabaya is the second-largest city in Indonesia and the development center in the eastern region has a large population and potential economy. This condition becomes the main attraction for job seekers from rural areas that contribute to increasing urbanization. It makes slum areas in several city corners. This condition is difficult to be controlled by the local government due to the limited funds to develop urban facilities and infrastructure. Low-income society can only live in uninhabitable places. Consequently, the regional government carries out the improvement of many slum areas. The people are moved to low-income flats. Even though they have different behavior and culture, they can live together. Most of them still have the same habits so they can adapt to each other. They think the flat environment as the rural one where they come from. It means that they can share each other to meet their needs. This can be seen through their behavior such as clustering and the kinds of activities.

The low-income flat is a high-rise building built and divided into sections. The functional structure is in a horizontal and vertical direction. The government does its best to achieve a goal that low-income people can survive independently. This flat is not the desirable choice for citizens and the government, but in general, it still provides qualified low-cost housing for the lower class people in urban areas. All of their needs can be accommodated. They just adapt to the existing environmental conditions. When living in the village they always do adaptation as a natural character.

In this low-income resident, there is a phenomenon as the expression of the implementation of their culture like togetherness. The placement of existing and created community spaces due to their unsuitable needs create an unorganized environment. This condition is evidence of mutual influence between the behavior, culture and the existence of community spaces outside the building. So if there is no compatibility with the culture, the community space will not be used optimally or its function will be changed.

There will always be a two-way relationship between space and culture in the apartment environment, so the unorganized phenomenon will still color the place. The cultural values such as the life philosophy creating togetherness, awareness of mutual assistance, and security control have a positive impact on the residents. Their activities in the existing environment will change from time to time as a process of adaptation carried out together in the community. The continuous habit applied will give identity to the outer space as the color of the place. The existence of the structured space (Lawson, 2001) is a concept of cultural transformation. It can produce a certain order according to the residents' behavior and culture. This condition is also applied to the existence of a shared space where they are interrelated.

Concerning the existence of outer space according to Rapoport (1977), it is necessary to have the basic observation of the community space, whether it is described as an abstract, free, or geometric form. The outer space is a part of a flat environment that its existence as a community space is outside the building. Togetherness in that space will decrease the area used privately by the residents. The 
community space that has its restrictions will decrease by the invasion of private space. Many low-income community spaces are built outside the building and used by the behavior and culture of the residents. The factors of location, accessibility, completeness of environmental facilities and infrastructure must provide the residents' satisfaction. The research aims to find out how the suitable placement of community space for the residents in the apartment environment can be used maximally. It is important to conduct a study on how to find out the existence of community space in the apartment environment that meets all the needs of users from low-income groups. The regulation of the behavior of these community groups is not always shaped by the existence of a permanent space in the flats. They need communal spaces outside of the buildings to meet flexibly their various needs.

\section{THEORY/RESEARCH METHODS}

Markus (2002) states that three important things underlie the system relating to the residents' community: form, function, and space. The criteria possessed by the community can be seen from the social relation and its strength, as well as the social structures. The social space structure outside the flats is to see how the residents use the community space. The residents' space structure shows cultural expression and behavior application. The utilization indications can be seen from the number of residents who use interrelated space. The changes in the social space structure must take into account Strauss's (2005) statement that material production and consumption must be balanced. The form of outer space structure and its meaning in a broader sense can be interpreted in various definitions. For example in the flat environment, it is distinguished between planned and unplanned spaces.

The existence of community space is a place where residents' culture is expressed in the behavior of low-income people. If the placement of the existence of community space is not compatible with the user's wishes, the place may not be used properly. It can even change its functions. The residents' togetherness activities can be done in the existing space. Some of them also spread to other places in the flat environment which attract their interest. It becomes unorganized. It creates the phenomenon of complexity as the identity of low-income people. This relates to the number of people who use community space. Consequently, the capacity of the existing community space is insufficient. This study requires observation and exploration. The method used is descriptive-qualitative-exploratory (Moleong, 2010). Information on the data about the placement of community spaces around the flat environment must pay attention to the user's material needs, whether it has been fulfilled. This study is conducted by a personal interview with the selected residents based on the mastery of the material needed. They include long- domiciled residents, community leaders and related bureaucrats who know the behavior and culture of the low-income people. Based on Lawson's phenomenology (2001), the activities of the research (Figure 1) are, such as:

a. Observing the residents' existing phenomena and giving explanations to the respondents. 
b. Writing down the meaning based on the experience of the researcher in revealing the current phenomenon.

c. Collecting data from competent respondents' answers, and strengthen the opinion of the study object observations

d. Analyzing all answers by grouping the respondents' statements.

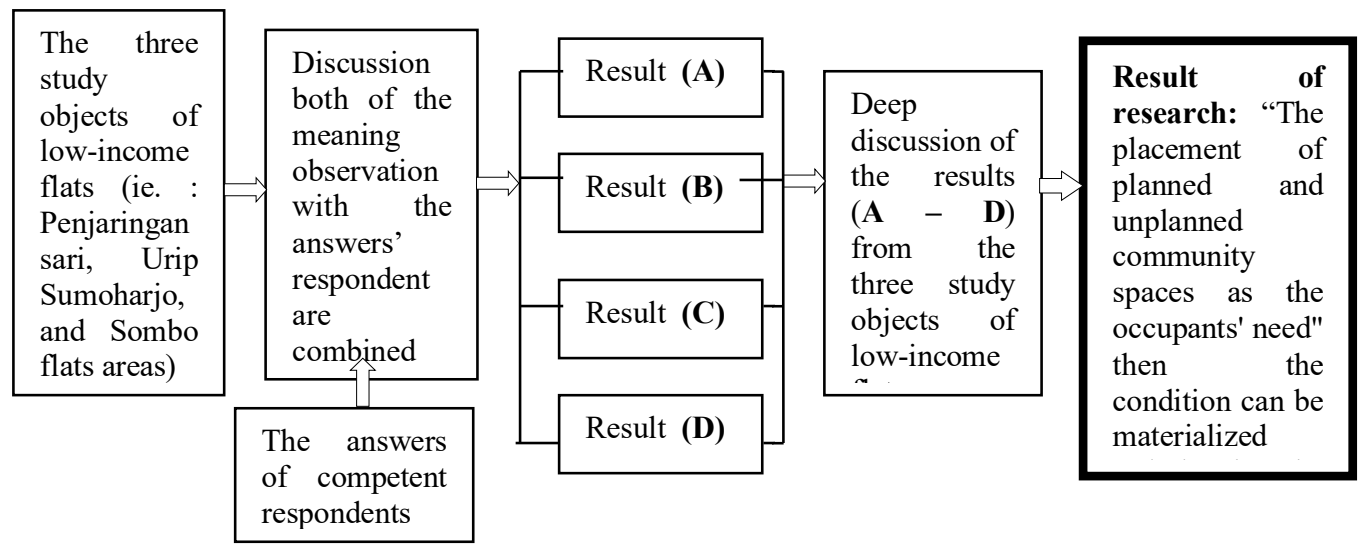

Figure.1 The Research Flowchart

From the observation carried out through the interaction of respondents in the flat environment, it can be found a phenomenon description of the residents' point of view (Moleong, 2010). The research method is using the related literature, inventorying the data of the object of study, making observations, interviewing respondents, having documentation strengthened by visual observation (primary data, behavior, and culture of low-income residents). The use of the interview method is to complete observation in the apartment area. The interview material is prepared to answer the research objectives. The theory used is to relate the research material. All the primary data can be corrected by the expert's statements based on the theory. The method of searching the data emphasizes on phenomenology to observe the existing meaning through field observation. This is the data input to strengthen other data for the analysis. The position of the researcher is to understand the various events carried out by residents in certain situations as the research object. Meanwhile, the field observations are carried out in three flat environments of lowincome residents as the object of study.

\section{RESULTS AND DISCUSSION}

Rapoport (2005) states that various activities carried out in space will form certain specifications. The arrangement will have an impact on its existence in an environment. The process of interaction between individuals, families, and society as a whole will produce a community space. The existence of space outside the building can be linked to each other because of the user's interconnection. Some of 
the planned community spaces in the flats are used but the others change their functions.

The activities outside the building are divided into special and routine activities, such as:

a. Residents' daily routine activities. It is the residents' daily activities in utilizing certain spaces.

b. The involvement of community members in the group. This activity is carried out by community members either independently or in groups. The activities are appropriate with the cultural expressions implemented in behavior.

c. Involvement of users in using the space as a routine activity. It can be carried out by individuals or groups whether in similar or different community spaces. The favorite rooms are used by most users at the same place.

d. Activities at the special location. The observation of activities taking place in certain locations can be assessed by the use of each space. It means that it is used permanently or not.

The observation shows that the tendency of residents to use existing community space is by their needs. All spaces can be used for various activities. It means that they represent multi-function togetherness. According to Rapoport (1969), a settlement is an institution that is not only structured but also made for a complex set of objectives. The place of togetherness is appropriate for the needs of the citizens. So the space used optimally will continue to be developed for other useful uses of the residents. The observation of study objects shows that flat environments have different residents' characteristics. Penjaringansari flat accommodates residents from various eviction locations. Meanwhile, Urip Sumoharjo flat accommodates the residents of the same area plus low-income people who have no place to live. Sombo flat only accommodates the residents from the same area. The three apartments show similar phenomena, while the difference is the use of community space. There is a community space used by residents who have business activities near the residential units. While the others use one community space shared with the other residents.

The utilization of community space outside the building used spontaneously by residents includes several places. For example, an expansion area of public facilities, which is a public facility, is used to meet some of the residents' needs. Especially on special days, this place is used by many people coming from several flats blocks. So it is necessary to expand the area. The planned community space with special functions is sometimes changed for different activities. The existence of a stall area on the ground floor of Block C of Phase II (Penjaringansari Flats) is actually for the residents' business. Now it changes its function to be a gen-set repair and motorcycle workshop. It is also used for a multipurpose room. The outer spaces within the flat or between flat blocks are also used for business (Figure 2). Similar conditions also occur in Urip Sumoharjo Flat. The planned community space in front of the flat facing Urip Sumoharjo Street does not function as a full food court. Some of them are empty. The residents prefer to sell their merchandise in front of their living units or use the outside space of the ground floor which is extended towards the outer space (Figure 3). Whereas, Block B of Sombo flat provides multistage market stalls at first. Unfortunately, they are not used and change their 
functions. Furthermore, the market service area is dismantled and used for the office buildings of the village, public health center, pre-school and the extension units of residents. The Sombo flat has a lot of open space in several locations. It makes the existence of the community space spread in several places (Figure 4).

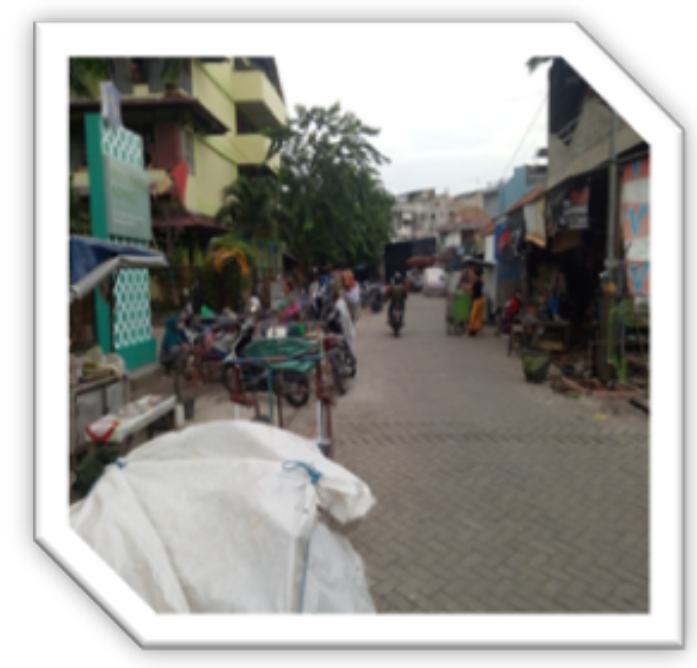

Figure. 2 The existence of open community spaces at the flat areas of Penjaringansari, Urip Sumoharjo, and Sombo (three of low-income flats in Surabaya) I

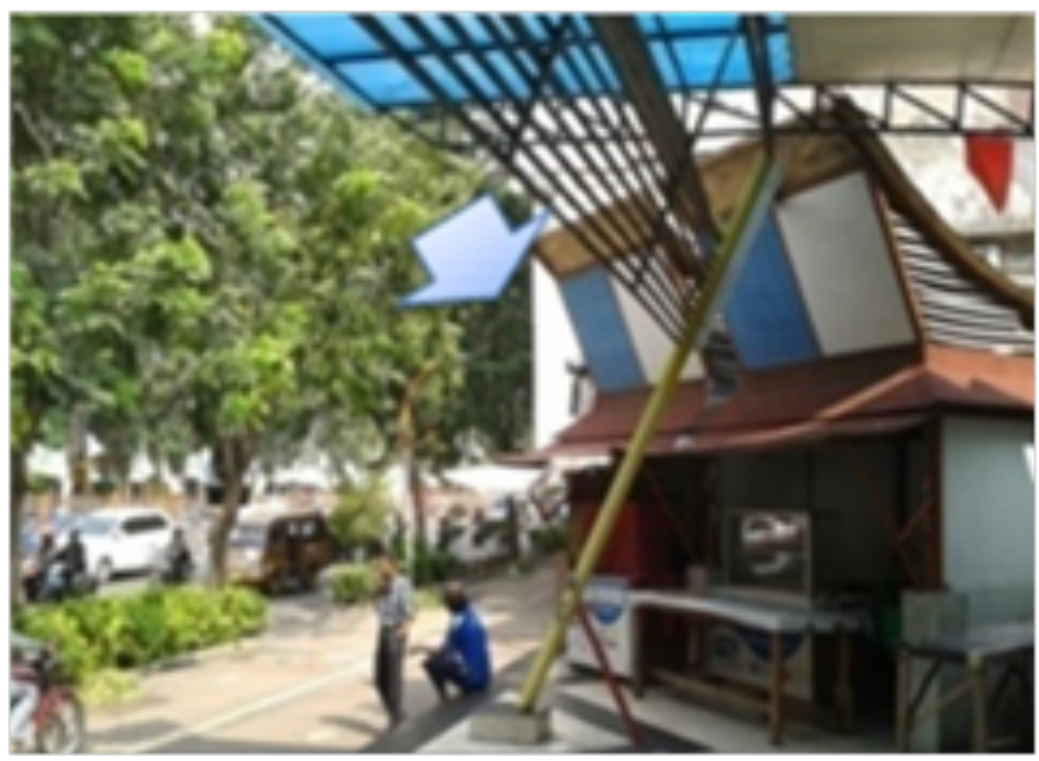

Figure. 3 The existence of open community spaces at the flat areas of Penjaringansari, Urip Sumoharjo, and Sombo (three of low-income flats in Surabaya) II 


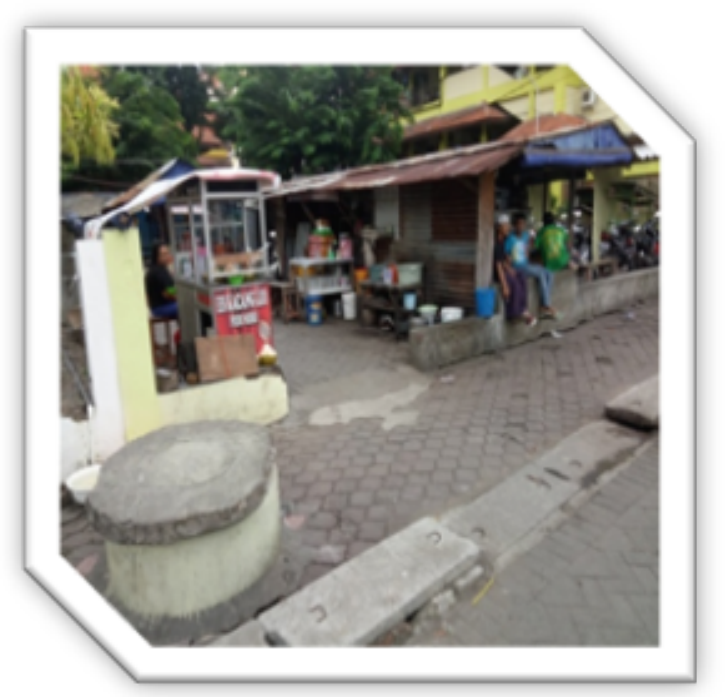

Figure. 4 The existence of open community spaces at the flat areas of Penjaringansari, Urip Sumoharjo, and Sombo (three of low-income flats in Surabaya) III

The open space of the flat area is used for various needs. Like at the Penjariansari flat, located near the highway, it is used by internal and external residents for market activities and children's play areas. Whereas on the special days of Islam and Indonesia's independence day, space is also used for the night market as entertainment for flat residents. The open spaces of the Urip Sumoharjo flat areas of Block A, B, and C are used for the residents' activities. On the special days of Islam, and Indonesia's independence day, they are used to meet the various needs of the citizens. The business activities by utilizing space between flats are carried out in groups or independently. The existence of community space on the ground floor can be extended to the outside of the flat area. It causes an unorganized condition. The open space of Sombo flats is scattered in several locations. For togetherness activities, the resident will choose a suitable location. (Source: References of Sombo Flat, KMS, 1989).

By Rapoport's (1977) statement, the characteristics of the cognitive scheme also include places that sometimes are not suitable with existing rules. The users of activities in the flats show the phenomenon of the togetherness of the residents. It takes place in spaces to relax, playgrounds, sports, the residents' small businesses, and the area of overseeing the security. The independence of small businesses is carried out on the expansion of residential units and outside spaces between flats or adjacent to the area outer fence. The purpose of selling the merchandise on the flats borders is to accommodate buyers from outside the flat area. Thus the items can be sold entirely. The phenomenon of togetherness activities sometimes accumulates in open spaces the users are interested in as shown in the following three study objects shown in figure 5 . 

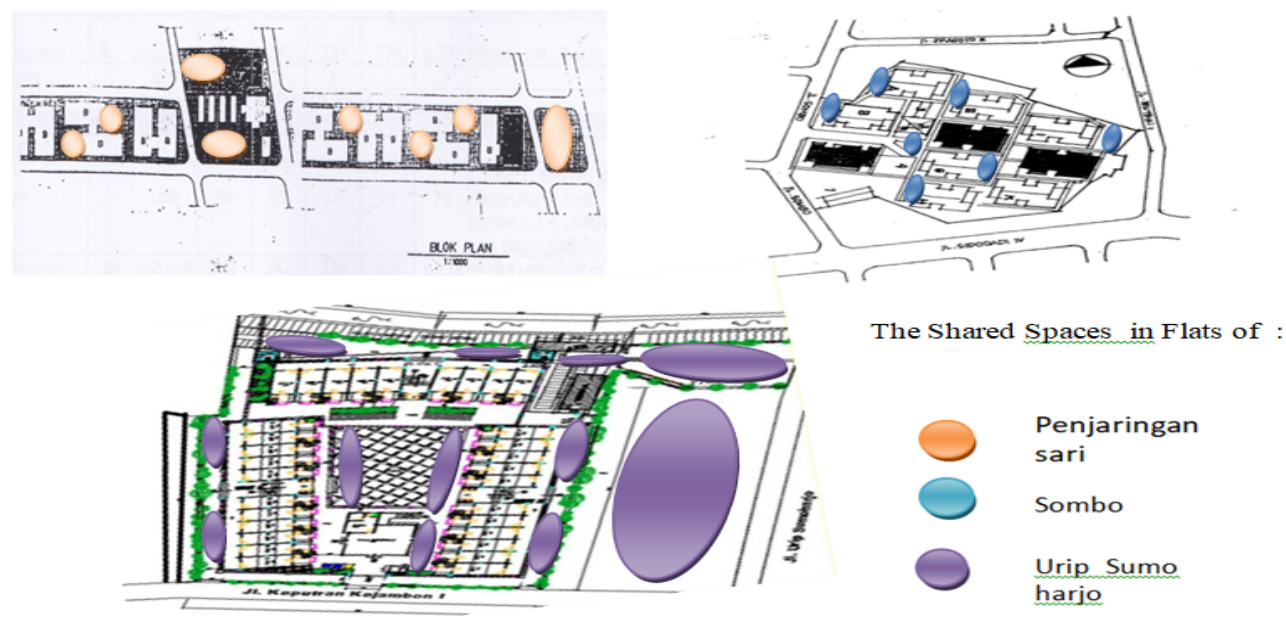

Figure 5. The Community Spaces in the Neighborhood of Flat Areas

If there are more than 5 respondents who provide information with different times and people, then data that are interrelated and strengthen the "statement" between each other will be obtained from the results of the interview, so that the results of the observation is close to the truth (Lhalauw, 2008).

From the results of interviews with several respondents of the three flats, it is concluded that:

a. Community space for togetherness is to meet the various needs of low-income residents. It can be seen that housewives in the flat area have a big responsibility. They have many tasks to fulfill all needs, such as caring for children and helping their husbands in earning a living. This demands the existence of a community space that can be accessed and seen easily. It is not obstructed by anything so that the residents do not hesitate to join.

b. Community space is a forum for expressing the residents' behavior and culture. They do not like formal behavior. If all aspects both behavior and culture are adjusted to the place where they gather, then all activities in the place can run optimally.

Kent (1989) states that a settlement is used as a place to store all things and to rest for the occupants. It is very interesting that because of the limited economic conditions of its residents, the business activities are carried out both inside and outside the area. The community space in the flats will be more organized if it is adjusted to the permanent residents' wishes as users. This condition had a positive impact on the equal distribution of residents' activities concentrated inside and outside the residential unit. Thus, the use of community space will not move to another place.

Management of flat area by managers is carried out by creating rules applied equally to all residents without distinguishing them. They who come from various tribes have their traditions. This sometimes makes them unable to integrate with others from different ethnic groups. But because they have the same background, low-income group, they can finally come together. 
This study is conducted through several processes using the basic study concept. The conceptualization of data is obtained through observation. All discussions will be related to theories as to the basis and the main research from the object of the study. From the observations, the finding is that there is a correlation between the existence of community space and the behavior of residents both in the planned and unplanned spaces. By understanding this condition, the existence of community space in the flat area is more organized. Furthermore, the condition of the flat will be more organized, especially if the community space is used optimally by its users.

\section{CONCLUSIONS}

Observations made on three flats as the object of the study indicate that phenomena are illustrating the existence of togetherness and residents' communality. Based on the behavioral and cultural phenomena of apartment residents, it can be concluded that: Humans as social beings tend to communicate with one another. This can be seen in the low-income community who prioritizes togetherness, kinship and care for one another. Poerwanto (1987) states that settlement is a residence prepared carefully as a means to achieve life goals. So it provides prosperity for the citizens. The residents' cultural roots cannot be separated from their originality. It will continue to unite in the lives of citizens despite being in a new location. All kinds of decisions in using the community space is adjusted to the behavior and culture of the citizens. The decision on land selection by users is based on the initial perceptions and motivations of the citizens. The point is that the use of community space is adjusted to the wishes of the residents

The various factors influencing the existence of community space are such as ethnicity, religion, education, and traditions brought by each occupant. The existence of community space is satisfactory if there is a match between the characteristics of each user and space utilization. There is a phenomenon of showing the culture expressed in the residents' behavior in flats. It arises "sense of place", where the use of open space as a community space is adjusted to the needs of the apartment residents coming from various regions in meeting their needs.

The existence of the planned community space is not fully used to meet the residents' needs. Based on the observation, it is sometimes not appropriate with their needs and behavior. Silas (1990) states that behavior and culture cannot be separated from each other. If the existence of the community space is not adaptive to the behavior and culture of the user, it will be left blank or change to other functions.

The existence of unplanned community spaces is used for togetherness and other activities to meet the needs of users. The discussion shows this space is used maximally by the residents. If the activities carried out by themselves in this space are interesting, they can be further developed by fulfilling other togetherness. This condition makes the other residents not hesitate to join and run their business in that place, as a form of developing togetherness activities.

If there is a relationship between planned and unplanned community space, it can be concluded that the behavior and culture of the residents are fully expressed. 
Space is maximally utilized. Togetherness activities will not move elsewhere and become more organized. Thus, the atmosphere and conditions of the apartment area become organized.

The behavior and culture of low-income communities must be applied in the planned community space by using an approach to its users. The existence of the initial design of the apartment area has been based on the perceptions and motivations of potential users. But it is still considered inadequate and does not represent the needs of citizens. The community space in a flat area is a space for implementing community togetherness. If the residents find inappropriate behavior, they will search for a more suitable place to meet their needs. They must get the opportunity to choose an alternative location in the apartment area. The existence of a community space that is very suitable for low-income residents will be used for routine togetherness that continues to grow. This condition is by Lang's (1987) theory that the habits or preferences that take place in each room are based on certain motivations. It subsequently will be processed in synapomorphy. The alignment of behavior with its physical settings in the community togetherness can be seen in the suitability. The choice of environment is influenced by the communal living space and its relation to the level and social status of the community. The togetherness of citizens that takes place in the community space is the center of all activities in the apartment area.

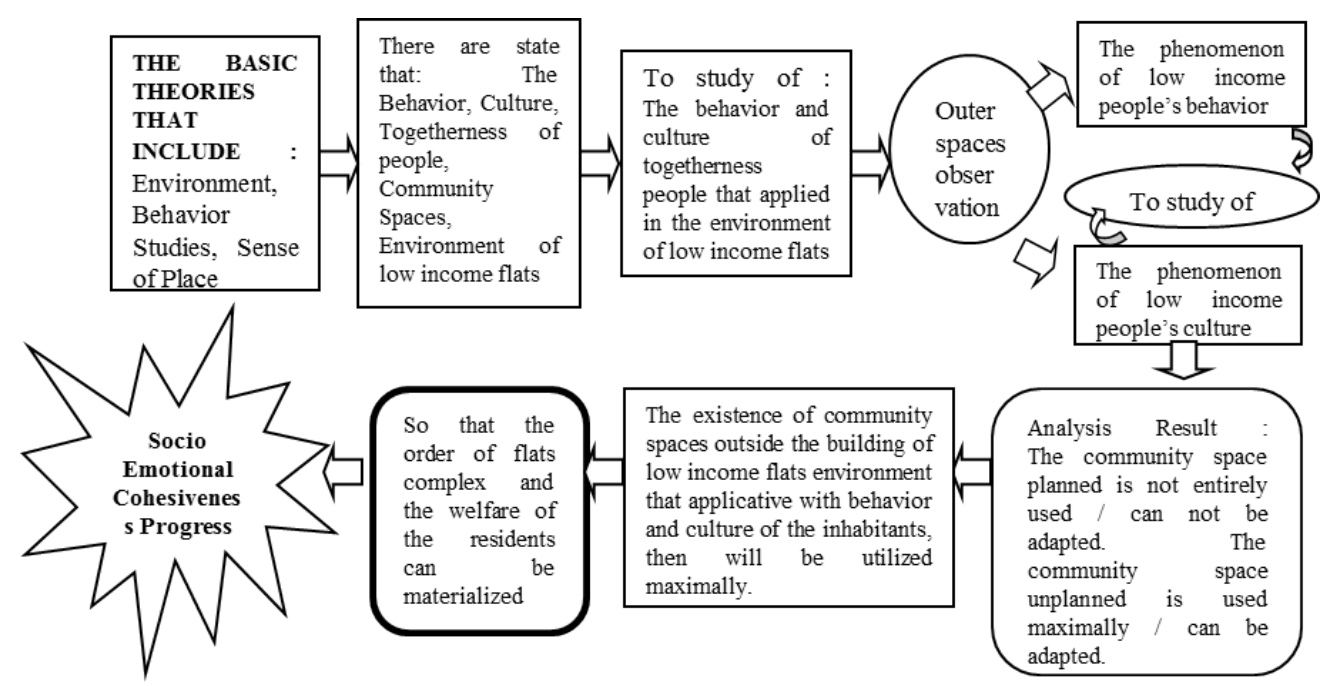

Figure.6 Flowchart of Research Finding

\section{REFERENCES}

Kent, S. (1989), Domestic Architecture and The Use of Space, Anthropology Program, Old Dominion University, Norfolk, Virginia. 
Kota Madya Surabaya (1989), Term of Reference Pekerjaan Perencanaan / Perancangan Pada Proyek Pembangunan Rumah Susun di Sombo Kelurahan Simolawang Kecamatan Simokerto Simokerto Surabaya, di Surabaya.

Lang, J. (1987), Creating Architectural Theory, The Role of The Behavioral Sciences in Environmental Design, Copy, Van Nostrand Reinhold Company Inc. Lawson, B. (2001), The Language of Space, Architectural Press, Oxford.

Lhalauw,J.O.I.,J.(2008), Konstruksi Theori, PT Grasindo, Jakarta.

Markus, T.A. (2002), The Words Between The Space: Building And Language, Routledge Publishing, New York.

Moleong ,L.,J.(2010), Metodologi Penelitian Kualitatif, PT Remaja Rosdakarya Bandung

Pemerintah RI, Menteri Perumahan Rakyat (1985), Undang Undang Republik Indonesia No.16 Tentang Rumah Susun di Indonesia.

Poerwanto, H. (1997), Manusia, Kebudayaan Dan Lingkungan, Direktorat Jenderal Pendidikan Tinggi Depdikbud RI dan Pusat Penelitian Lingkungan Hidup, Universitas Gajah Mada, Yogyakarta.

Rapoport, (1969), House Form and Culture, Englewood Clifts, New York, PrenticeHall.

Rapoport, (1977), Human Aspect of Urban Form, Pergamon Press, New York.

Rapoport, A. (2005), Culture Architecture, and Design, Lock Science Publishing Inc, Chicago.

Strauss, C. (1990), Basics of qualitative Research : Grounded Theory Procedures and Technique, Sage Publication, Newbury Park, California, USA.

Silas, J. (1990), Kampung Surabaya Menuju Metropolitan, ITS, Surabaya. 
Darmiwati: THE EXISTENCE OF COMMUNITY SPACES OUTSIDE THE FLAT BLOCK AFFECTED BY ACTIVITIES OF LOW-INCOME RESIDENTS

This Page is Intentionally Left Blank 